\title{
A view from the bodies corporate. 2. OrthoWorld 2000 Ltd
}

\section{F. Stuart-Wilson}

\begin{abstract}
North London may seem an unlikely venue for a discussion about orthodontics which takes us as far afield as South Africa and the USA, but Edgware is where I find the head office of OrthoWorld. At the time of writing OrthoWorld are the only specialist body corporate in the UK. I am meeting Dr. Morris Fine, Director of Operations, a quietly spoken orthodontist - and still practising - with what turns out to be strong views and clear convictions. OrthoWorld had its beginnings 'four and a half years ago. Three of us started the venture, an orthodontist, an ex-dentist and a business man'. Morris Fine is the orthodontist, and the other two of the triumvirate are Jack and Reuben Shapiro respectively. Morris Fine tells that they 'had headed up a successful media company in South Africa before turning their attention to orthodontics in the UK'
\end{abstract}

It is at this point that Morris Fine introduces the name, Orthodontic Centers of America (OCA). It appears that they were a model for OrthoWorld, and the name features heavily during the course of the interview. Looking back after subsequent inter-

Name: Morris Fine
Qualified: University of Witwatersrand,
South Africa
Title: Operations Director
Company: OrthoWorld 2000 Ltd (a plc)
Established 1999
Head Office: Edgware, North London
Number of practices: 18
Clinical profile: NHS/private
orthodontics
Current turnover: $€ 6-7$ million
Website address:
www.orthoworld.co.uk

views with other dental directors, I realise it is the only interview where a clear distinct existing business model is discussed. It is clear however, that Morris Fine admires OCA, and he is able to quote some interesting facts and figures about them, and later draws comparisons between the US and UK orthodontic markets.

The body corporate was acquired at the end of March 1999, and OrthoWorld now have 18 practices UK wide, from Southampton to Aberdeen. Their most recent acquisition is in Hampstead and the company intends to continue its expansion programme. 'In the last year we have upgraded a practice a month' explains Morris. 'Acquiring the body corporate allowed us to have shareholders and get funding. Rothschild Investment Trust are our biggest investors and orthodontics is attractive to investors.' He goes on to expand on his view that dentistry needs investment. 'The NHS fees are totally inadequate. Good medicine and good dentistry costs money - it is very expensive if you do it properly.'

\section{'The NHS fees are totally}

inadequate. Good

medicine and good

dentistry costs money - it is very expensive if you do it properly.'

The differences between the UK and US markets becomes apparent as Morris continues to talk about the development of OrthoWorld, and I am interested that the directors have used OCA as a business model.

'The orthodontic spend in the US is approximately $\$ 9$ billion. In the UK it is 


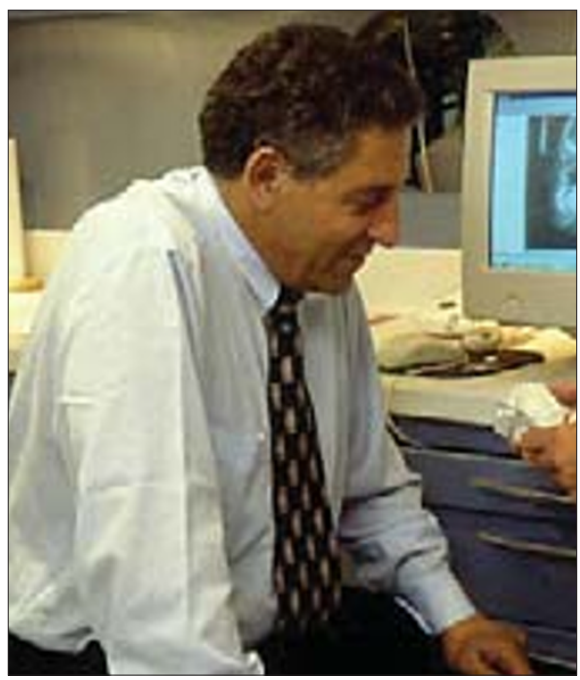

Morris Fine, Operations Director

approximately $£ 100$ million. The population is four times the size but the number of orthodontic cases per capita is fewer. OrthoWorld's turnover is £6-7 million this year and we expect a substantial increase in the next year, anything from 7-10 million. If you look at OCA, they are probably the most successful healthcare company in the world; at their peak in the US their market value was $\$ 1.6$ billion.

\section{It has not all been plain}

sailing however. 'We've

had bad times... We

\section{should break even some}

\section{time next year.'}

Morris Fine is happy to reveal that it has not all been plain sailing however. 'We've had bad times. We were told that it would be hard to get the thing going. We should break even some time next year.

It is easy to see where some of that investment has gone. 'It costs between $£ 250,000$ and $£ 300,000$ to set up a practice. Practices have digital X-rays, digital cameras, computer systems, there is a touch of amusement in Morris's voice as he continues, 'We have had quite an influence on some of the market. If they were honest, our profile is very high amongst orthodontists. There is some negativity, possibly due to jealousy.' He dismisses this lightly, politely, reasoning, 'there's room for everyone, the singlehanded practitioner, the partnership, the corporate - no one model is right.'

The OrthoWorld corporate survey that I later read in some detail is certainly very positive about its image and ethos. Dr. Jack Shapiro is quoted as saying "As the only dental corporate dedicated to ortho-

\section{'It costs between}

\section{$£ 250,000$ and $£ 300,000$}

\section{to set up a practice.'}

dontics we set out to improve other standards in orthodontic care in the UK from treatment through to customer care.' These words are to be echoed a few days later in some of the first remarks that Julian Perry from the Ora dental group makes during my interview with him.

As the company grows, so the remuneration profile of OrthoWorld is also changing. The OrthoWorld practices' offering is an NHS/private split. 'At the moment about $10 \%$ of work is private. That accounts for about 35\% of income, and is increasing all the time. If we continue to get low NHS fees it will be difficult to do good work. We have to do four NHS cases to achieve the same income as one private case.'

Some of their practices however, have a higher private profile. 'The Harley Street practice is completely private; Maidenhead is nearly $50 \%$ private. All adults are seen privately.'

I ask Morris about his acquisition criteria. He sets out an apparently simple framework but I sense that defining that framework more specifically is more complex than he reveals.

'We look for a practice with a name that does reasonable work. We look for the position, the location.' This second criterion is reminiscent of my discussion with Jitesh Patel of ADP. However, his third reason is more surprising. "We look at the person running it. We look for personal qualities - do the people also have potential?'

The word potential appears again. 'We seek potential for growth. We now prefer acquisition to squats as a growth strategy, and we are looking at some bigger practices.' That does not mean that some of

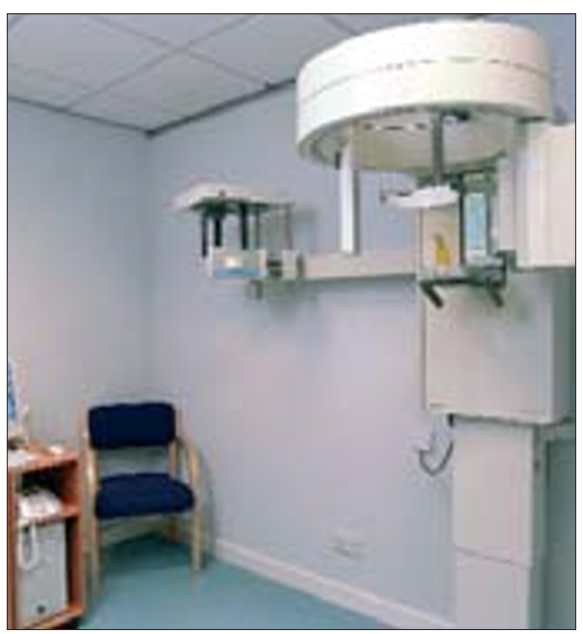

A typical x-ray room at OrthoWorld practices. the squats are lagging behind. 'Chelmsford - a startup - is now achieving 50 referrals a week in 15 months. That's good.'

His next comments are almost identical to those of other dental directors and I begin to feel there is a moral to be learnt from this comment. 'We turn down practices that don't look good or where people demand too much.' He is polite in how he chooses his next words. 'Sometimes people are unrealistic about what can be fetched.'

\section{'there's room for}

\section{everyone, the single-}

handed practitioner, the

partnership, the corporate

\section{- no one model is right.'}

The company particularly likes practices with 'access to high net worth individuals, with A/B socio-demographics, close to schools. Demographics are particularly important for private work.'

'The ratio of squats/acquisition is about 50/50, and we have three practices on a profit sharing model. It's the way to go, and very similar to the States model.' He feels that there must be a change to the percentage model of remuneration. 'No more 50\%! We are looking to go down the profit-share route, so that people will have an interest in the costs.'

He goes on to describe in more detail the OrthoWorld practice. 'All our practices look the same - they are state-ofthe art, with a similar layout, but with some experimentation. Patients are aware that it is an OrthoWorld practice. We are trying to build a brand image. We want GDPs to be more aware of the brand. We've held open days for GDPs to introduce them to what's going on.'

He reflects 'The environment is very important. When I was a dentist I took a job at 5\% less than anywhere else because I liked the environment.'

People development within the practices is a recurring theme throughout the interview and development as far as Morris Fine is concerned starts with the board.

'The board is cross-trained! This adds value as it rejuvenates my ideas. I enjoy what I do. The orthodontists respect the fact that I can visualise the problems they are having. A team, including me, may go to assist the practice. I still practice in Portugal, and have a background in teaching. I keep the group up-to-date so that we are very well-informed with information from Europe and the US as well as the UK.' 


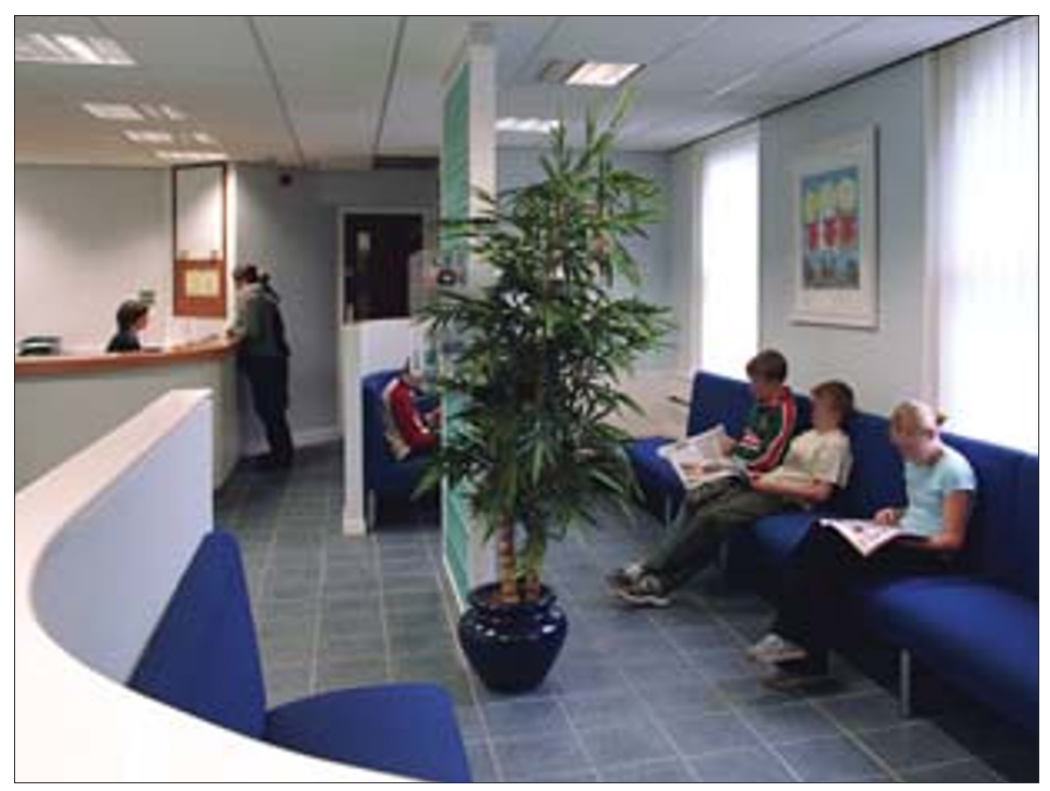

The reception area at the Taunton practice

'We encourage postgraduate education and have one or two get-togethers for all of the group. We have introduced new procedures and techniques.'

It seems important to Morris that he can continue to empathise with the orthodontists. I feel you could take the director out of the orthodontist but not the orthodontist out of the director. "We encourage autonomy in practices - we don't proscribe, we suggest. We give them a goal, the facilities to achieve that goal, encourage them and be a friend to them. If someone's doing something wrong, we talk to them.' He continues 'We monitor them and the team goes out and helps them - some need more guidance than others. We have a model that we feel works and the team goes out and helps the practices to achieve that model.'

He is relaxed about staffing issues, and outlines a situation of which many would be envious. 'One orthodontist has left to study in the US. One or two have returned. Staff retention is very high, and

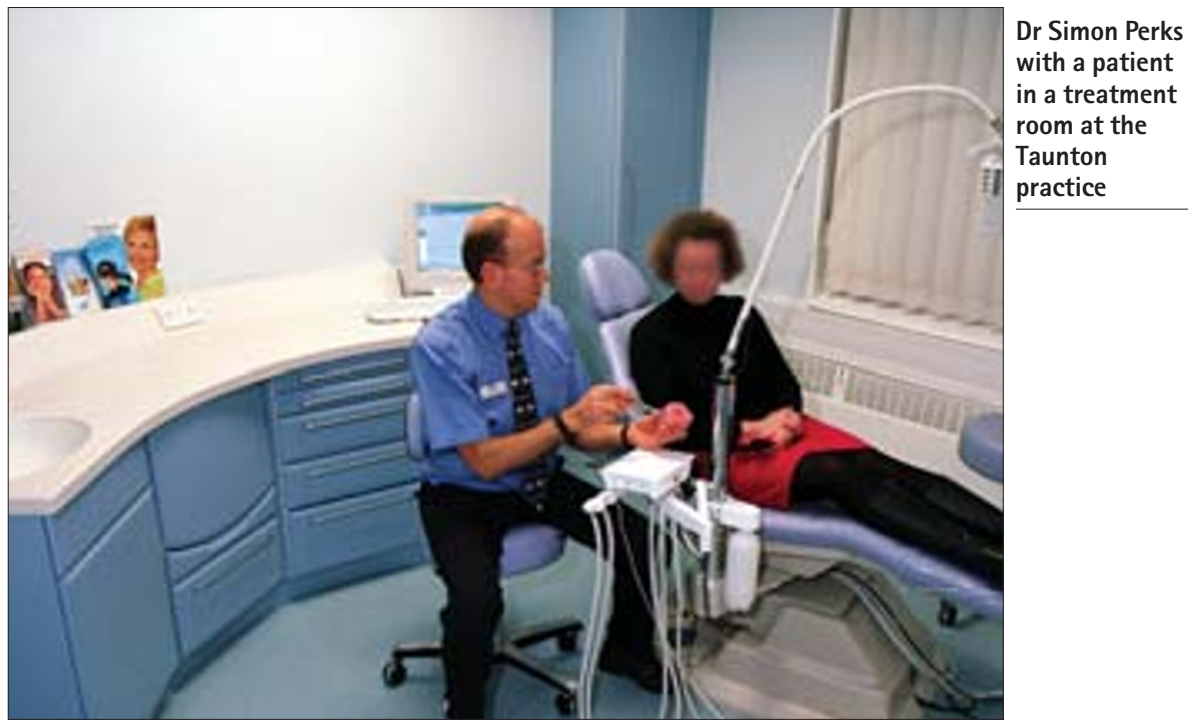

the key staff tend to stay.' He attributes this partly to opportunities for development, although he puts it another way when I suggest this. 'Give people an opportunity - they will develop themselves.'

After my interview with ADP, where Jitesh Patel talked about dentists in their forties wanting an exit route from their practices, I am interested in Morris's comments next. 'Experience counts - there's too much burnout amongst orthodontists of over 50 - we need that experience. It's a fun profession. Some of what I do now I do for fun - some not!'

We move on to the market for orthodontics as a prelude to looking to the future and his predictions. Morris believes 'The public are now more willing to pay for private orthodontics - a change is definitely taking place. There is a greater level of acceptance. In the US, cosmetic surgery can be used as an example. Sixty per cent of people who have cosmetic surgery are on a below average income.'
So far as the future is concerned he starts by considering the corporate structure.

'The corporates will still be there although some are battling at the moment. More specialist corporates? I can see a point where there are more specialist corporates, and specialisation focus in some of the existing corporates.'

\section{'The public are now more}

\section{willing to pay for private orthodontics - a change is definitely taking place.'}

'With people wanting to work in a good environment, the corporate structure gives them a good opportunity to develop in a good environment rather than spend a lot when they are already in debt.' He also sees some merging of corporates, 'perhaps even some overseas corporations moving in. We know the market and the type of thinking here and the changes required - we would be very attractive to an overseas corporate.' This is the first time that an international perspective has been put to me in these interviews and it is an unusual one.

Morris expresses his convictions about orthodontics. 'There will be an explosion in orthodontics. The adult market has yet to be tapped. Look at other areas - everyone's keen on gyms these days, and training, cosmetic procedures - orthodontics is the way to go, particularly with modern methods of appliances. Orthodontics is seen as an investment.'

He sees lack of information as a barrier currently. 'Most adults are not really aware that they can be treated. The economy will play a big role in what will happen. The 


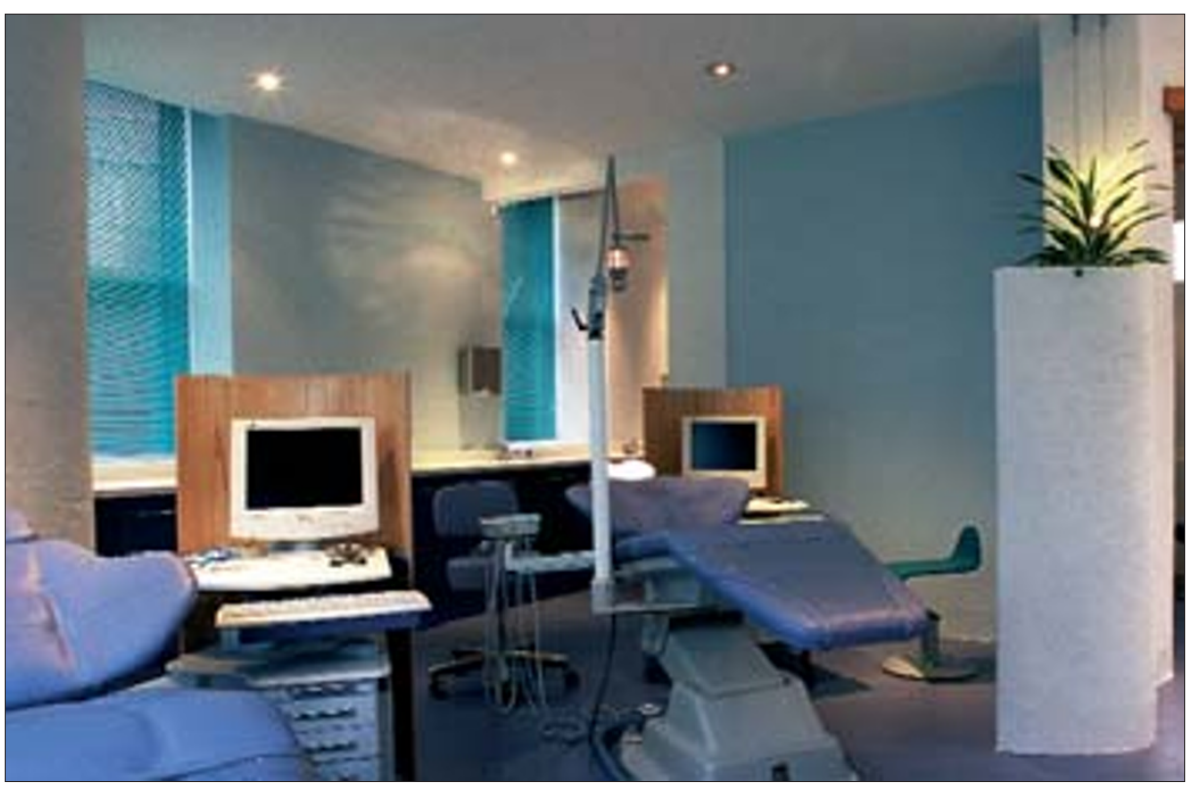

Government wants to push dentistry down the private route but is trying to do it in a subtle way. They'll keep it going somehow.' Is this the same view as Jitesh Patel's game of poker that he spoke about in my last interview? Morris's next words are reminiscent of nearly all of the directors that I speak to.

'People will be demanding higher levels of work and higher levels of service.' In Morris Fine's opinion, if government 'would improve their medical and dental fees they will be preventing ten times that amount on litigation.'
OrthoWorld currently uses assistants 'as much as legally possible' and Morris Fine sees an increase in this. 'Auxiliaries coming in soon will be the best thing that could happen to orthodontics. I can also see central clinics for x-rays.'

He also discusses better business training for dentists in the UK and again looks across the Atlantic for a precedent. 'US dental schools are considering business training,' and Morris Fine would certainly support this in the UK.

I reflect that much of this interview has been about potential - the market
The multiple chair treatment rom at the Dundee practice.

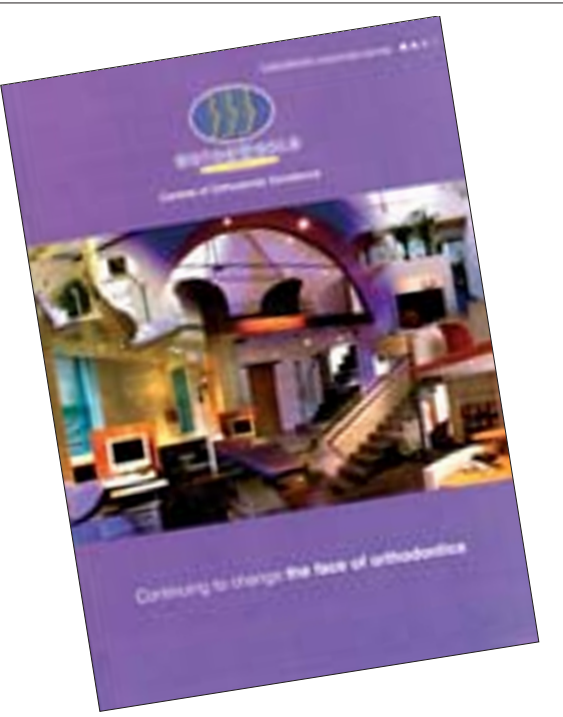

potential, the potential for orthodontics and interestingly, people potential.

Morris gives an impression of enjoying what he does, and I ask him what he finds are the main differences in his role as a director and his role previously as an orthodontist. He smiles and sums it up very neatly.

'I'm a capitalist with a social conscience! However, before if I was under pressure in the practice I could go home and leave it. Now as a director, I am under pressure 24 hours a day with so many responsibilities. We have to do the right thing for the shareholders:

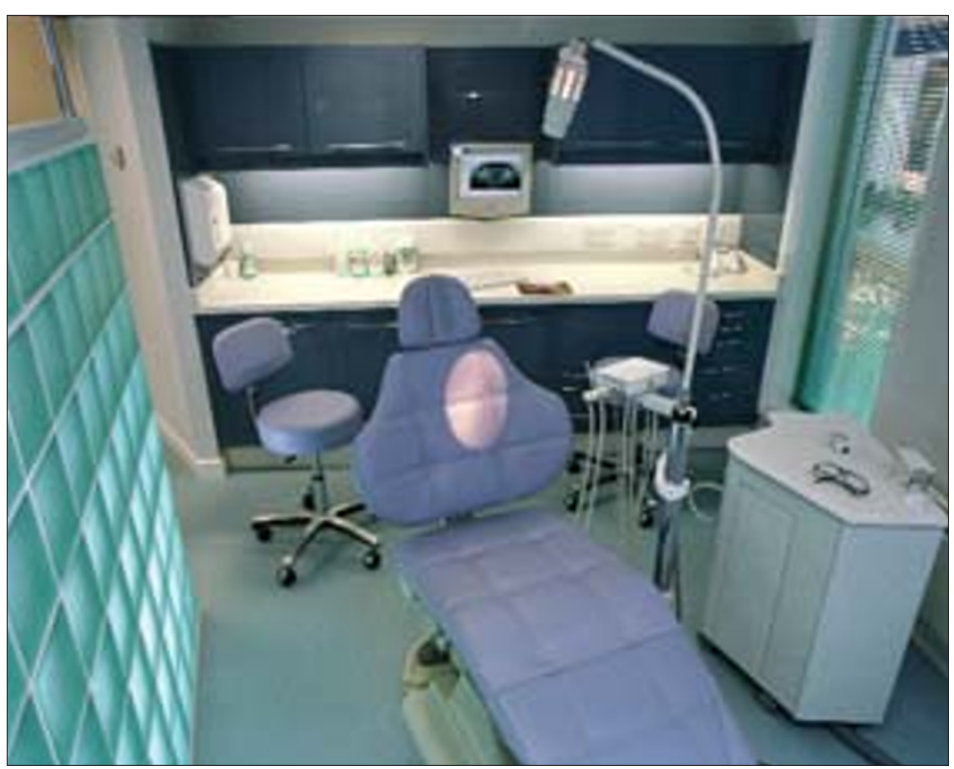

A treatment room at the Leamington Spa surgery

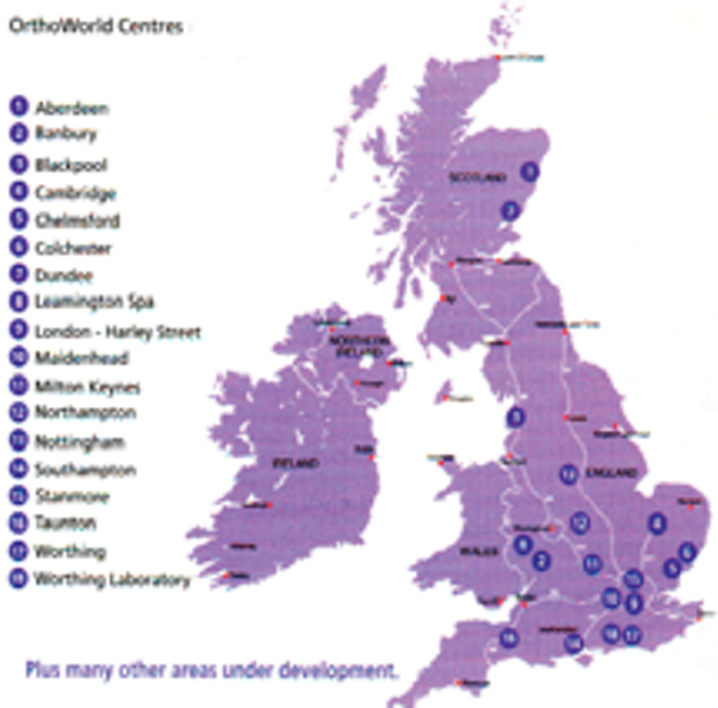

